\title{
Early hypophosphatemia in very low birth weight preterm infants
}

\author{
Agata Pająk ${ }^{B-D}$, Barbara Królak-0lejnik ${ }^{A, D-F}$, Agnieszka Szafrańska ${ }^{A, C, D}$ \\ Department and Clinic of Neonatology, University Hospital, Wroclaw Medical University, Poland \\ A - research concept and design; $\mathrm{B}$ - collection and/or assembly of data; $\mathrm{C}$ - data analysis and interpretation; \\ $D$ - writing the article; $E$ - critical revision of the article; $F$ - final approval of the article
}

\author{
Address for correspondence \\ Agata Pająk \\ E-mail:agata_pa@wp.pl \\ Funding sources \\ None declared

\section{Conflict of interest} \\ None declared

\section{Acknowledgements} \\ The authors would like to acknowledge \\ Beata Kołaczyńska for her involvement \\ in the laboratory diagnosis.
}

Received on August 30, 2016

Reviewed on February 15, 2017

Accepted on March 31, 2017

\begin{abstract}
Background. Refeeding Syndrome (RFS) is a well-known group of symptoms which occur after the introduction of enteral or parenteral nutrition in undernourished patients. Intrauterine growth restriction (IUGR) is the equivalent of postnatal RFS following the beginning of feeding. The aggressive parenteral nutrition of neonates with very low birth weight (VLBW) resulting from the termination of intrauterine transplacental nutrition is a source of biochemical disorders.
\end{abstract}

Objectives. The aim of this study was to analyze metabolic disorders in preterm infants during the $1^{\text {st }}$ week of life and to determine the hypophosphatemia risk factors in low birth weight neonates receiving parenteral nutrition. The retrospective analysis covered 49 neonates, aged between 240/7 and 32 6/7 weeks of gestation.

Material and methods. The examined patients were divided into 2 groups according to the level of phosphates during the $1^{\text {st }}$ week of life: HP $(n=18)$ with aggravated hypophosphatemia $(\leq 3.1 \mathrm{mg} / \mathrm{dL})$ and NP $(n=31)$ with normal phosphatemia $(>3.1 \mathrm{mg} / \mathrm{dL})$.

Results. Hypophosphatemia was observed in the first days of life in 61\% of children, in 45\% of whom a subsequent test revealed a further fall in the phosphate level. In the rest of the preterm neonates (39\%), hypophosphatemia was revealed between the 4th and 7th day of life. The risk of early hypophosphatemia was higher in neonates with IUGR ( $p=0.0001$; RR 5.2, 95\% Cl 2.2-12.4) and extremely low birth weight (ELBW) preterm infants $(p<0.05)$.

Conclusions. Early hypophosphatemia should be closely monitored early in life, especially in newborns with ELBW and IUGR. Further research is needed to develop an optimal nutritional regimen from the first days of life.

Key words: nutrition, neonatology, hypophosphatemia, metabolic, preterm infant

DOI

10.17219/acem/70081

\section{Copyright}

Copyright by Author(s)

This is an article distributed under the terms of the

Creative Commons Attribution Non-Commercial License

(http://creativecommons.org/licenses/by-nc-nd/4.0/) 


\section{Introduction}

Nutrition is an essential element in the intensive care of preterm newborns. Not only does it affect the results of treatment, but it also influences susceptibility to diseases in adulthood and it has lifelong cognitive impact. The aim of administering aggressive parenteral nutrition is to promote continued growth (increased weight and length) equivalent to that of a fetus's normal intrauterine life. ${ }^{1-4}$ Refeeding Syndrome (RFS) is a well-known group of symptoms which occur after the introduction of enteral or parenteral nutrition in undernourished patients. RFS can be prevented by the correction of electrolyte disorders and by vitamin B intake at the beginning of nutrition. ${ }^{5,6}$ The symptoms result from the quick conversion of catabolic metabolism to anabolic - from the transformation of free fatty acids and ketones released during the transformation of bicarbonates as a primary source of energy. ${ }^{7,8}$ Intrauterine growth restriction is the equivalent of postnatal RFS after nutrition has begun. Aggressive parenteral feeding of neonates with very low birth weight (VLBW) resulting from the interruption of intrauterine transplacental nutrition is a source of biochemical disorders.

The term Placental Incompletely Restored Feeding syndrome (PI-ReFeeding syndrome) was proposed for preterm newborns because of the lack of adequate intake of other nutrients in relation to amino acids and energy. Amino acids are responsible for an increase in the production of endogenous insulin. Insulin induces intracellular redistribution of phosphates and potassium, which leads to the lowering of their concentration in blood serum. Moreover, the acceleration of anabolism results in the increased reprocessing of phosphates and potassium. ${ }^{9}$ The clinical implication of hypophosphatemia are multi-system disorders occurring mainly in energy-active organs; thus, heart or respiratory failure, muscle hypotension, neurological symptoms, hematological disorders, insulin-resistant hyperglycemia, or metabolic acidosis may occur. However, indications for the modification of the phosphate intake of nutritional treatment, which, according to current recommendations, are introduced on the $3^{\text {rd }}$ day of a neonate's life, have not yet been established.

The aims of this study were:

- to analyze metabolic disorders in preterm infants during the $1^{\text {st }}$ week of life, especially hypophosphatemia; and

- to determine the hypophosphatemia risk factors in low birth weight neonates receiving parenteral nutrition.

\section{Material and methods}

The research was carried out from August 2013 to July 2014 in the Neonatal Intensive Care Unit of the Department of Neonatology at the University Hospital in Wrocław. During this period, 2,316 neonates were hospitalized in the department, 84 of whom were born before $330 / 7$ weeks of gestation, which constituted $3.6 \%$ of all labors. The retrospective analysis covered 49 neonates aged between 24 0/7 and 32 6/7 weeks of gestation. The study included children whose phosphate concentration was measured at least twice during the $1^{\text {st }}$ week of their lives: between the $1^{\text {st }}$ and $3^{\text {rd }}$ day of life (M1), and between the $4^{\text {th }}$ and $7^{\text {th }}$ day of life (M2). Patients with congenital malformations were excluded from the analysis. Two groups of neonates were identified by means of Fenton centile growth charts for preterm neonates: appropriate for gestational age (AGA) and small for gestational age (SGA). ${ }^{10}$

Starting parenteral nutrition sets were prepared by the hospital pharmacy and contained amino acids $(1.5 \mathrm{~g} / \mathrm{kg})$, glucose and calcium $(0.5 \mathrm{mmol} / \mathrm{kg})$, but no phosphates. According to the Guidelines for Paediatric Parenteral Nutrition published by the European Society for Paediatric Gastroenterology, Hepatology and Nutrition (ESPGHAN) in 2005, a minimum amino acid intake of $1.5 \mathrm{~g} / \mathrm{kg} /$ day is necessary to prevent a negative nitrogen balance. ${ }^{11} \mathrm{~Pa}-$ tients in the study received amino acids $(3.0 \mathrm{~g} / \mathrm{kg} /$ day $)$ and lipids $\left(3 \mathrm{~g} / \mathrm{kg} /\right.$ day) from the $2^{\text {nd }}$ day of life.

The patients received Glycophos (Fresenius Kabi, Uppsala, Sweden) in parenteral nutrition from the $2^{\text {nd }}$ or $3^{\text {rd }}$ day of life (range: $2^{\text {nd }}-5^{\text {th }}$ day of life), according to current recommendations. ${ }^{11}$

Phosphate supplementation was continued in the form of human milk fortifier and/or a sodium-phosphate mixture in all enterally-fed patients with hypophosphatemia.

A phosphate level $<4.4 \mathrm{mg} / \mathrm{dL}(1.4 \mathrm{mmol} / \mathrm{L})$ in preterm neonates in the $1^{\text {st }}$ week of life was diagnosed as hypophosphatemia. Severe hypophosphatemia was set at a phosphate level of $<3.1 \mathrm{mg} / \mathrm{dL}$ ( $1 \mathrm{mmol} / \mathrm{L})$, and hypocalcemia and hypomagnesemia were diagnosed at calcium and magnesium levels $<8.0 \mathrm{mg} / \mathrm{dL}$ and $1.5 \mathrm{mg} / \mathrm{dL}$, respectively. The biochemical tests on blood serum were performed using the Beckman Coulter analyzer (Beckman Coulter Polska Sp. z o. o., Warszawa, Poland) in the Department of Analytical Laboratory of the University Hospital in Wrocław.

The Bioethical Commission of Wroclaw Medical University granted permission to carry out the retrospective analysis of the patients' medical records.

The characteristics of the examined patients, divided into 2 groups according to the level of phosphates (HP aggravated hypophosphatemia, $\leq 3.1 \mathrm{mg} / \mathrm{dL}$; and NP - normal phosphatemia, $>3.1 \mathrm{mg} / \mathrm{dL}]$ ) are presented in Table 1 .

Statistical analyses were performed using either version $\mathrm{N}-1$ of the $X^{2}$ test for categorical variables, or the Mann-Whitney test or Student's t-test for continuous variables. The data was expressed as mean \pm SD for normally distributed continuous variables, or as median and range for variables not normally distributed. Categorical variables were described using absolute (n) and relative (\%) frequencies. For categorical variables, the relative risk (RR) was calculated with 95\% confidence intervals $(\mathrm{CI})$. Simple and multiple regression were also used. A p-value $<0.05$ was considered significant. 
The analysis was performed using Stargraphics Centurion XVII (Stargraphics Technologie Inc., Virginia, USA) and MedCalc v. 16.2 (MedCalc, Ostend, Belgium) for Windows.

\section{Results}

A phosphate concentration in blood serum within the proper laboratory range (4.4-6.7 mg/dL) was observed in only $25 \%$ of infants. A value below the lower range limit was observed in $75 \%$ of neonates, and in 2 children (4\%) phosphate concentration barely exceeded the upper range limit (Fig. 1).
Hypophosphatemia was observed in the first days of life in $61 \%$ of children, in $45 \%$ of whom a subsequent test revealed a further fall in the phosphate level. In 39\% of the examined preterm neonates, hypophosphatemia was recognized between the $4^{\text {th }}$ and $7^{\text {th }}$ day of life (Fig. 2).

On the basis of phosphate concentration, the neonates were divided into 2 groups: those with aggravated hypophosphatemia $(\leq 3.1 \mathrm{mg} / \mathrm{dL})$ and those with normal phosphatemia $(>3.1 \mathrm{mg} / \mathrm{dL})$.

The median concentration of phosphates in 1-3-dayold newborns' blood serum was $3.1 \mathrm{mg} / \mathrm{dL}$ in the $\mathrm{HP}$ group and $5 \mathrm{mg} / \mathrm{dL}$ in the NP group; however, in the tests

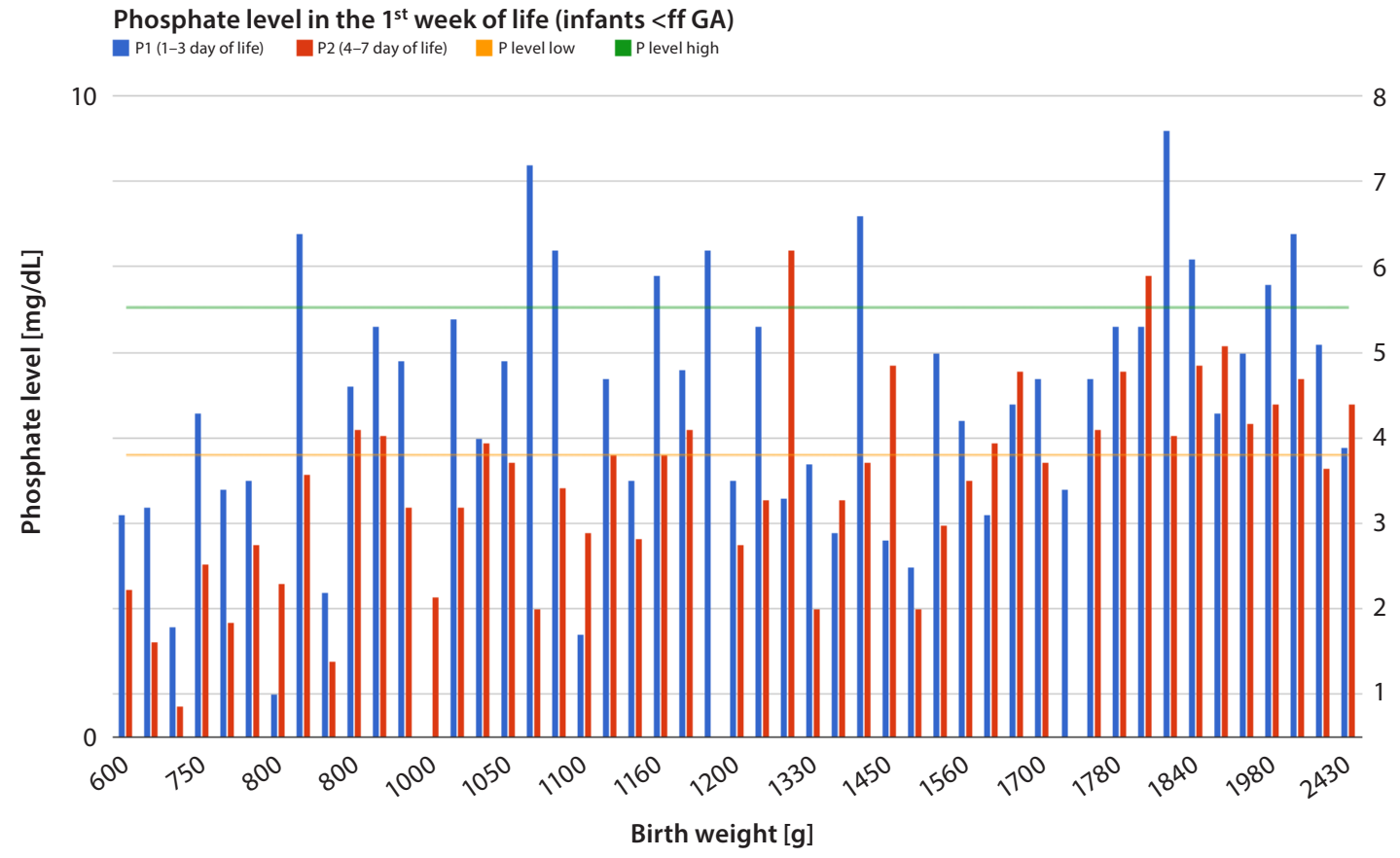

Fig. 1. Phosphate concentration in blood serum of preterm infants

green line - upper range limit; orange line - lower range limit, blue column - level of phosphates in the $1^{\text {st }-3^{\text {rd }}}$ day of life; red column - level of phosphates in $4^{\text {th }}-7^{\text {th }}$ day of life.

Table 1. Characteristics of the preterm infants: A comparison of HP and NP

\begin{tabular}{|c|c|c|c|c|}
\hline Characteristics & $\begin{array}{c}\text { HP } \\
(n=18)\end{array}$ & $\begin{array}{c}N P \\
(n=31)\end{array}$ & $\mathrm{RR} 95 \% \mathrm{Cl}$ & $p$-value \\
\hline Gestational age weeks, mean \pm SD & $29.2 \pm 2.2$ & $29.8 \pm 2.4$ & - & $0.3576^{t}$ \\
\hline $\mathrm{GA}<28 \mathrm{HBd}, \mathrm{n}(\%)$ & $3(17)$ & $7(23)$ & $\begin{array}{c}\text { RR } 0.74 \\
\text { Cl } 0.22-2.50\end{array}$ & $0.6215^{x}$ \\
\hline Birth weight $[g]$, mean $\pm S D$ & $1029 \pm 315$ & $1477 \pm 447$ & - & $0.0005^{t}$ \\
\hline Small for gestational age, n (\%) & $11(61)$ & $3(10)$ & $\begin{array}{c}\text { RR } 6.32 \\
\text { CI } 2.03-19.68\end{array}$ & $0.0002^{x}$ \\
\hline $\begin{array}{l}\text { TPN } \\
\text { initial glucose intake }[\mathrm{g} / \mathrm{kg} / \mathrm{day}] \text {, mean } \pm \mathrm{SD}^{1} \\
\text { initial amino acids intake }\left[\mathrm{g} / \mathrm{kg} / \text { day], mean } \pm \mathrm{SD}^{1}\right. \\
\text { initial P intake }[\mathrm{mmol} / \mathrm{kg} / \mathrm{day}] \text {, median ( range) } \\
\text { initial K intake }\left[\mathrm{mmol} / \mathrm{kg} / \text { day], median (range) }{ }^{2}\right.\end{array}$ & $\begin{array}{l}8.97 \pm 1.24 \\
2.72 \pm 0.31 \\
3(1-5) \\
3(2-5)\end{array}$ & $\begin{array}{l}8.89 \pm 1.21 \\
2.69 \pm 0.45 \\
4(2-5) \\
4(2-7)\end{array}$ & $\begin{array}{l}- \\
- \\
- \\
-\end{array}$ & $\begin{array}{c}0.8192^{\mathrm{t}} \\
0.7891^{\mathrm{t}} \\
0.7273^{\mathrm{M}-\mathrm{W}} \\
0.0528^{\mathrm{M}-\mathrm{W}}\end{array}$ \\
\hline Days of TPN (for survivors), median (range) & $13(5-30)$ & $10.5(3-35)$ & - & $0.3919^{M-W}$ \\
\hline Days of hospital stay (for survivors) & $53(31-89)$ & $35(15-104)$ & - & $0.0324^{\mathrm{M}-\mathrm{W}}$ \\
\hline
\end{tabular}

HP - study group; NP - control group; $\mathrm{n}$ - number of patients; RR - relative risk; Cl - confidence interval; SD - standard deviation; GA - gestational age; $\mathrm{HBd}$ - hebdomas; TPN - total parenteral nutrition; ${ }^{x} \mathrm{X}^{2}$ test; t Student's t-test; ${ }^{\mathrm{M}-\mathrm{W}}$ Mann-Whitney test. 
carried out between the $4^{\text {th }}$ and $7^{\text {th }}$ day of life, the concentrations were $2.35 \mathrm{mg} / \mathrm{dL}(\mathrm{HP})$ and $5.5 \mathrm{mg} / \mathrm{dL}(\mathrm{NP})$. The lowest level of phosphates was observed up to the $10^{\text {th }}$ day of life (median: the $6^{\text {th }}$ day of life). The neonates received phosphates in parenteral nutrition from the $3^{\text {rd }}$ day of life (range: $2^{\text {nd }}-5^{\text {th }}$ day of life). Phosphorus supplementation was continued in the form of human milk fortifier and/or a phosphate-sodium mixture in all patients with hypophosphatemia.

There was a statistically significant relationship between the minimum level of phosphorus $\left(\mathrm{P}_{\min }\right)[\mathrm{mg} / \mathrm{dL}]$ and birth weight [g] with a 95\% CI; p-value $<0.05$ ( $\mathrm{p}=0.0000)$.

$\mathrm{P}_{\min }[\mathrm{mg} / \mathrm{dL}]=-14.6492+2.53301 \times \ln ($ birth weight $[\mathrm{g}])$

The $\mathrm{R}^{2}$ value indicates that the model as fitted explains $46.3533 \%$ of the variability in $\mathrm{P}_{\min }[\mathrm{mg} / \mathrm{dL}]$ after transforming to a $\mathrm{Y} /(1-\mathrm{Y})$ scale to linearize the model. The correlation coefficient equals 0.680833 , indicating a moderately strong relationship between the variables (Fig. 3).

Neonates with intrauterine growth restriction (IUGR) (RR 5.2 95\% CI 2.2-124; p = 0.0001) and extremely low birth rate $(\mathrm{ELBW})(\mathrm{p}<0.05)$ were at risk of early hypophosphatemia; however, the difference in gestational age between the NP and HP groups was statistically insignificant.

Even though insulin, catecholamine and invasive ventilation were more frequently administered, and complications such as intraventricular hemorrhages (IVH), early infections, bronchopulmonary dysplasia (BPD), death, or biochemical disorders (hypertriglyceridemia, hypocalcemia or hyperglycemia) occurred more often in the HP group than in the NP one, they were statistically insignificant.

\section{Discussion}

Considering the problem of hypophosphatemia in neonates, the question of how and when to diagnose it must be answered.

The assessment of hypophosphatemia is necessarily based on the level of phosphorus in serum; thus, it is vital to be fully familiar with the normal range. It is also essential to bear in mind pre-analytical errors - sample hemolysis falsely increases the phosphate concentration results, as do hypertriglyceridemia and hyperbilirubinemia in intensive care unit patients. The phosphate concentration in a fetus's blood may be adopted as the golden standard for determining a preterm neonate's biochemical condition. ${ }^{12}$ Based on the assessment of phosphate concentration in 560 neonates' umbilical blood, Fenton set referential values for preterm newborns and term-born babies dependent on gestational age within 4 age ranges. The lower range limit for preterm neonates with 28-31 weeks of gestation was $1.4 \mathrm{mmol} / \mathrm{L}$, the same as in our study. However, the upper range limit in our study was higher than that in Fenton (2.7 vs $2.1 \mathrm{mmol} / \mathrm{L}$ ). In neonates, the norms depend on gestational age; phosphate concentration in umbilical blood decreases with GA, while the level of sodium increases.

Adults are also considered to develop serious symptoms at phosphorus levels lower than 1-1.5 mg/dL $(<0.32-$ $-0.5 \mathrm{mmol} / \mathrm{L}){ }^{8,13}$ In the developmental period, however, phosphatemia norms depend on age - the lower the age, the higher the norms. The highest values are observed in babies, so extrapolation seems inaccurate. Safe phosphatemia ranges in neonates, especially in VLBW ones, need to be determined in the near future. Both the frequency and intensity of the described disorders in a specific study

8

P2-P

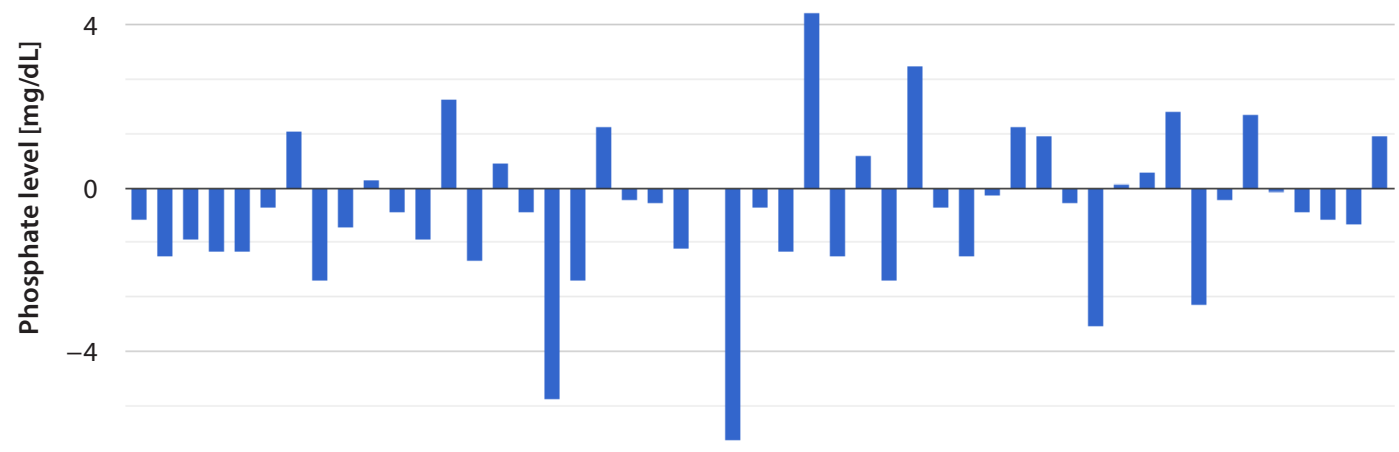

$-8$

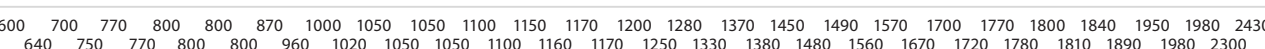

Birth weight [g]

Fig. 2. Difference in phosphate level depending on the body weight of newborn infants 
are influenced by the range of the adopted norm. In order to increase the possibility of revealing hypophosphatemia complications, we used aggravated hypophosphatemia (defined as a phosphorus level of $<1 \mathrm{mmol} / \mathrm{L}$ ) for the purpose of statistical analysis. In publications, hypophosphatemia is set at various phosphorus concentrations ranging from $<0.8 \mathrm{mmol} / \mathrm{L}$ to $\leq 0.9 \mathrm{mmol} / \mathrm{L}$ or $\leq 1 \mathrm{mmol} / \mathrm{L} .{ }^{9,14-16}$

Therefore, which level should require intensive phosphate supplementation? In other words, when should hypophosphatemia be diagnosed? It may be necessary to review the results of the studies conducted with metabolic methods, which can precisely pinpoint the ranges of clinically significant hypophosphatemia. . $^{17,18}$

Just 10 years ago, hypophosphatemia in neonates, as well as in babies, was associated with a metabolic bone disease diagnosed at the end of the $1^{\text {st }}$ month of life; and in the early neonatal period, this age group was actually expected to develop hyperphosphatemia.

On the basis of both our own studies and published works, it may be concluded that after changing the nutrition protocol, hypophosphatemia is not a rare complication in VLBW infants and it often occurs in the $1^{\text {st }}$ week of life. ${ }^{9,14,19-21}$ The early hypophosphatemia observed in VLBW infants and those who are small for gestational age (SGA) suggest that it may have the same mechanism as RFS. VLBW neonates with sepsis require special attention, because they present even lower values of phosphorus concentration in blood. ${ }^{14,20}$ Three out of 4 neonates from our study group diagnosed with sepsis within the first 2 weeks of life had pronounced early hypophosphatemia $(<3.1 \mathrm{mg} / \mathrm{dL})$; 2 of them died. Transient hypophosphatemia is also observed in both children and adults in the course of diagnosed infections; phosphorus concentration is inversely proportionate to C-reactive protein (CRP) level, so other anti-inflammatory factors are said to take part in the process (tumor necrosis factor alpha and interleukin 6). ${ }^{22,23}$ When should phosphorus concentration be monitored, then? Unfortunately, there are no generally accepted protocols, but there is increasing evidence which indicates that it is important to measure phosphate concentration within the first days of life. ${ }^{4,15,21}$ However, the number of additional tests in infants is limited not only by indications for their use, but also by the amount of circulating blood and the risk of iatrogenic anemia. There are suggestions that phosphate concentration should be monitored twice a day before stabilization. ${ }^{24}$ Other authors argued for monitoring the clinical and biochemical parameters of RFS in the $3^{\text {rd }}$ or $4^{\text {th }}$ day of life in infants at risk, including VLBW or ELBW neonates requiring parenteral nutrition. ${ }^{19}$

Based on the data which we obtained, the $1^{\text {st }}$ measurement of phosphorus should be taken by the $3^{\text {rd }}$ day of life and it should be retaken every 2 or 3 days within the $1^{\text {st }}$ week of life due to the risk of increased hypophosphatemia. While correcting acute hypophosphatemia, the concentration in blood serum should be measured $2 \mathrm{~h}$ after infusion. ${ }^{8}$ The dose and timing of phosphorus intake in parenteral and enteral feeding with a high protein and energy intake is crucial in order to avoid RFS in infants. ${ }^{25}$ In neonatology, tailored nutrition prescriptions

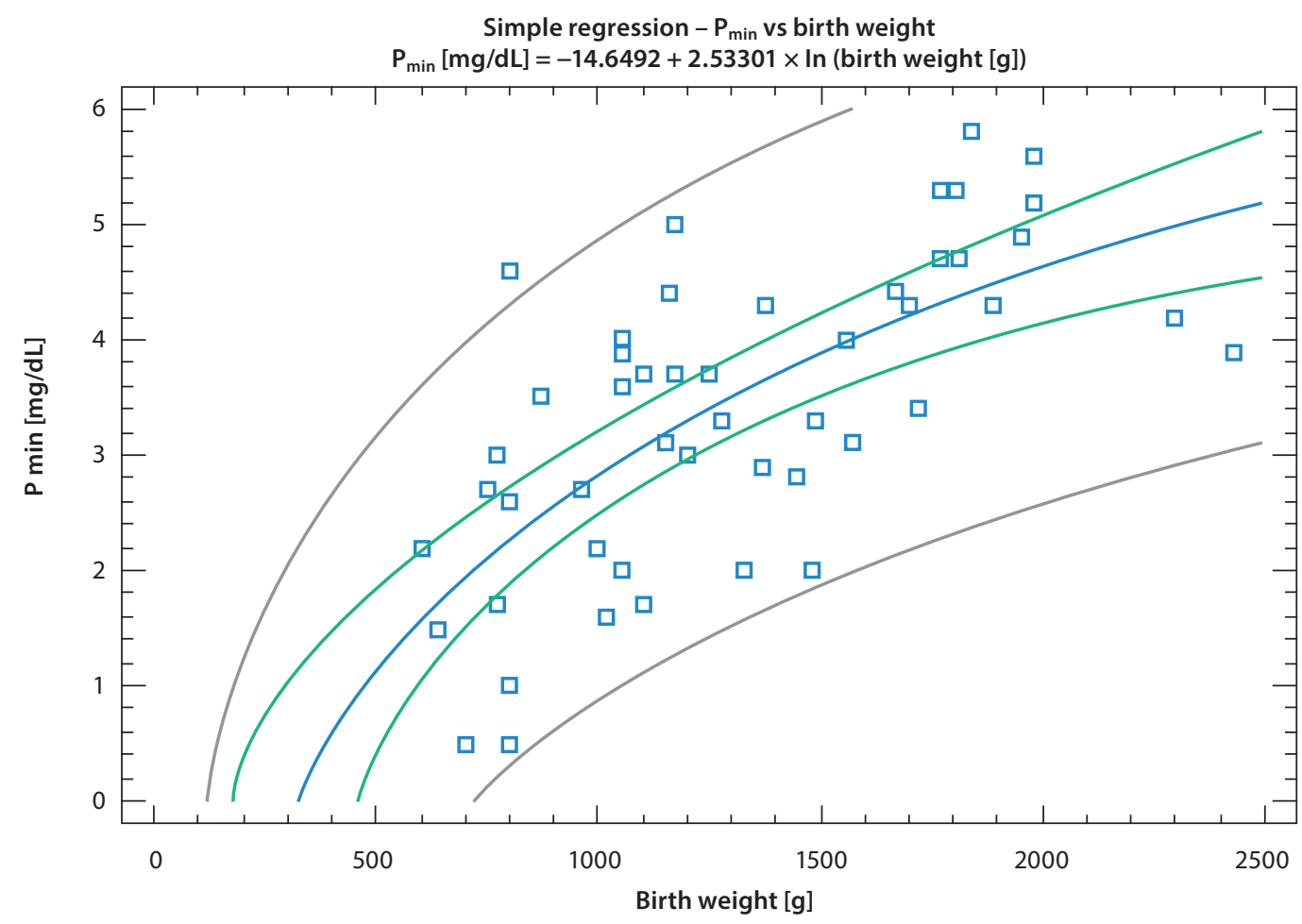

Fig. 3. Relationship between $P_{\min }[\mathrm{mg} / \mathrm{dL}]$ in blood serum during the $1^{\text {st }}$ week of life and birth weight [g] of the preterm infants 
are typically administered. More and more data advocate intake safety from the $1^{\text {st }}$ day of standard nutrition which contains phosphates. ${ }^{26-28}$ However, phosphorus supplementation is currently recommended from the $3^{\text {rd }}$ day of life; before that, neonates receive only a small amount of phosphorus in a lipid solution. Fears of early phosphate intake result from the need to intake sodium and potassium simultaneously, which is not recommended in the first days of life until diuresis stabilizes. The complications from phosphorus intake, especially intravenous feeding, also include hypocalcemia and excess intake resulting in hyperphosphatemia. ${ }^{11}$ It is important to point out that regardless of phosphate supplementation, a decrease in phosphate concentration was observed in 66\% of preterm neonates with parenteral nutrition older than 3 days of life whom we examined, a fact that indicates insufficient intake. While performing parenteral intake of $\mathrm{Ca}$ or $\mathrm{P}$ in the amount of 3 and $1.92 \mathrm{mmol} / \mathrm{kg} /$ day, respectively, in the $3^{\text {rd }}$ day of life, Christman et al. administered the maximum recommended phosphate doses to preterm infants <34 GA; however, as many as $34 \%$ of babies had a phosphorus level of $<1.8 \mathrm{mmol} / \mathrm{L}$ in the $5^{\text {th }}$ day of life. ${ }^{21}$

The study we carried out is a preliminary one. The small group of patients studied made it impossible for us to present conclusive results concerning RFS clinical symptoms in preterm neonates with aggravated hypophosphatemia. Prospective studies are currently being conducted in our center.

\section{Conclusions}

Early hypophosphatemia is a common metabolic complication in neonates with $<33 \mathrm{GA}$ who receive parenteral feeding. Thus, thorough monitoring is necessary from the very first days of life, especially in VLBW and SGA neonates. It is necessary to carry out further studies in order to determine optimal nutritional standards in the early stages of life. It is also essential to identify risk groups of infants who may have higher requirements for supplemented phosphates within the $1^{\text {st }}$ week of life to prevent RFS.

What is new:

- adequate phosphate intake is important for prevention of metabolic bone disease in preterm infants;

- recommendations for neonatal mineral intake are based on in utero acceleration rates, but supplementation requirements of preterm neonates vary between studies.

What is known:

- early hypophosphatemia is a common metabolic complication in neonates before 32 GA receiving parenteral nutrition;

- thus, thorough monitoring is necessary from the very first days of life, especially in VLBW and SGA neonates.

\section{References}

1. Adamkin D, Radmacher P. Current trends and future challenges in neonatal parenteral nutrition. J Neonatal Perinatal Med. 2014;7:157-164.

2. Nehra D, Carlson S, Erica M, et al. The American Society for Parenteral and Enteral Nutrition ( ASPEN) clinical guidelines: Nutrition support of neonatal patients at risk for metabolic bone disease. J Parenter Enteral Nutr. 2013;37:570-598.

3. Hay WW, Jr. Aggressive nutrition of the preterm infant. Curr Pediatr Rep. 2013;1(4):222-239. doi:10.1007/s40124-013-0026-4

4. Embleton ND, Morgan C, King C. Balancing the risks and benefits of parenteral nutrition for preterm infants: Can we define the optimal composition? Arch Dis Child Fetal Neonatal Ed. 2015;100:F72-F75.

5. Crook MA, Hally V, Panteli JV. The importance of the refeeding syndrome. Nutrition. 2001;17:632-637.

6. Khan LU, Ahmed J, Khan S, Macfie J. Refeeding syndrome: A literature review. Gastroenterol Res Pract.2011;410971. doi:10.1155/2011/410971

7. Skipper A. Refeeding syndrome or refeeding hypophosphatemia: A systematic review of cases. Nutr Clin Pract. 2012;27:34-40.

8. Byrnes MC, Stangenes J. Refeeding in the ICU: An adult and pediatric problem. Curr Opin Clin Nutr Metab Care. 2011;14:186-192.

9. Bonsante F, lacobelli S, Latorre $G$, et al. Initial amino acid intake influences phosphorusus and calcium homeostasis in preterm infants: It is time to change the composition of the early parenteral nutrition. PLOS ONE. 2013;8:e72880. doi:10.1371/journal.pone.0072880

10. Fenton TR, Kim JH. A systematic review and meta-analysis to revise the Fenton growth chart for preterm infants. BMC Pediatr.2013;13:59. doi:10.1186/1471-2431-13-59

11. Koletzko B, Goulet O, Hunt J, Krohn K, Shamir R. Guidelines on Paediatric Parenteral Nutrition of the European Society of Paediatric Gastroenterology, Hepatology and Nutrition (ESPGHAN) and the European Society for Clinical Nutrition and Metabolism (ESPEN), supported by the European Society of Paediatric Research (ESPR). J Pediatr Gastroenterol Nutr. 2005;41:1-87.

12. Fenton TR, Lyon AW, Rose MS. Cord blood calcium, phosphate, magnesium, and alkaline phosphatase gestational age-specific reference intervals for preterm infants. BMC Pediatr. 2011;11:76. doi:10.1186/1471-2431-11-76

13. Sikora P. Phosphataemia disturbances in children. Pediatr Dypl. 2014;18:37-44.

14. Moltu SJ, Strømmen K, Blakstad EW, et al. Enhanced feeding in verylow-birth-weight infants may cause electrolyte disturbances and septicemia: A randomized, controlled trial. Clin Nutr. 2013;32:207-212.

15. Ross JR, Finch C, Ebeling M, Taylor SN. Refeeding syndrome in verylow-birth-weight intrauterine growth-restricted neonates. J Perinatol. 2013;33:717-720.

16. Boubred F, Herlenius $E$, Bartocci $M$, et al. Extremely preterm infants who are small for gestational age have a high risk of early hypophosphatemia and hypokalemia. Acta Paediatr. 2015;104:1077-1083.

17. Moco S, Collino S, Rezzi S, Martin FP. Metabolomics perspectives in pediatric research. Pediatr Res. 2013;73:570-576.

18. Alexandre-Gouabau MC, Courant F, Moyon T, et al. Maternal and cord blood LC-HRMS metabolomics reveal alterations in energy and polyamine metabolism, and oxidative stress in very-low-birth-weight Infants. J Proteome Research.2013;12:2764-2778.

19. Mizumoto $H$, Mikami M, Oda H, Hata D. Refeeding syndrome in a small-for-dates micro-preemie receiving early parenteral nutrition. Pediatr Int.2012;54:715-717.

20. Brener Dik PH, Galletti MF, Fernández Jonusas SA, et al. Early hypophosphatemia in preterm infants receiving aggressive parenteral nutrition. J Perinatol. 2015;35:712-715.

21. Christmann V, de Grauw AM, Visser R, Matthijsse RP, van Goudoever JB, van Heijst AF. Early postnatal calcium and phosphorusus metabolism in preterm infants. J Pediatr Gastroenterol Nutr. 2014;58:398-403.

22. Antachopoulos C, Margeli A, Giannaki M, et al. Transient hypophosphataemia associated with acute infectious disease in paediatric patients. Scand J Infect Dis. 2002;34:836-839.

23. Naffaa ME, Mustafa M, Azzam M, et al. Serum inorganic phosphorous level predict 30-day mortality in patients with community acquired pneumonia. BMCInfectDis.2015;15:332. doi:10.1186/s12879-015-1094-6

24. Koletzko B, Poindexter B, Uauy R. Nutritional care of preterm infants: Scientific basis and practical guidelines. Indian J Med Res. 2016;143(4):531-532. doi:10.4103/0971-5916.184296 
25. Lafeber HN, van de Lagemaat M, Rotteveel J, van Weissenbruch M. Timing of nutritional interventions in very-low-birth-weight infants: Optimal neurodevelopment compared with the onset of the metabolic syndrome. Am J Clin Nutr. 2013;98:556-560.

26. Jamin A, D'Inca R, Le FN, et al. Fatal effects of a neonatal high-protein diet in low-birth-weight piglets used as a model of intrauterine growth restriction. Neonatology. 2010;97:321-328.

27. Bolisetty S, Pharande P, Nirthanakumaran L, et al. Improved nutrient intake following implementation of the consensus standardized parenteral nutrition formulations in preterm neonates before-after intervention study. BMC Pediatr. 2014,14:309. doi:10.1186/s12887-014-0309

28. Imel EA, Econs MJ. Approach to the hypophosphatemic patient. $J$ Clin Endocrinol Metab. 2012;97:696-706. 